\title{
Determining Antigen Specificity of Human Islet Infiltrating T Cells in Type 1 Diabetes
}

\author{
Maki Nakayama and Aaron W. Michels* \\ Barbara Davis Center for Childhood Diabetes, University of Colorado School of Medicine, Aurora, CO, United States
}

\section{OPEN ACCESS}

Edited by:

Clemencia Pinilla,

Torrey Pines Institute for Molecular

Studies, United States

Reviewed by:

Anne Cooke

University of Cambridge,

United Kingdom

Bruce Milne Hall,

University of New South Wales,

Australia

*Correspondence:

Aaron W. Michels

Aaron.Michels@ucdenver.edu

Specialty section:

This article was submitted to

T Cell Biology,

a section of the journal

Frontiers in Immunology

Received: 14 September 2018

Accepted: 13 February 2019

Published: 08 March 2019

Citation:

Nakayama M and Michels AW (2019) Determining Antigen Specificity of Human Islet Infiltrating T Cells in Type

1 Diabetes. Front. Immunol. 10:365.

doi: 10.3389/fimmu.2019.00365
Type 1 diabetes, the immune mediated form of diabetes, represents a prototypical organ specific autoimmune disease in that insulin producing pancreatic islets are specifically targeted by $T$ cells. The disease is now predictable in humans with the measurement of type 1 diabetes associated autoantibodies (islet autoantibodies) in the peripheral blood which are directed against insulin and beta cell proteins. With an increasing incidence of disease, especially in young children, large well-controlled clinical prevention trials using antigen specific immunotherapy have been completed but with limited clinical benefit. To improve outcomes, it is critical to understand the antigen and $T$ cell receptor repertoires of those cells that infiltrate the target organ, pancreatic islets, in human type 1 diabetes. With international networks to identify organ donors with type 1 diabetes, improved immunosequencing platforms, and the ability to reconstitute $T$ cell receptors of interest into immortalized cell lines allows antigen discovery efforts for rare tissue specific $T$ cells. Here we review the disease pathogenesis of type 1 diabetes with a focus on human islet infiltrating $T$ cell antigen discovery efforts, which provides necessary knowledge to define biomarkers of disease activity and improve antigen specific immunotherapy approaches for disease prevention.

Keywords: diabetes, autoimmunity, HLA, insulin, T cells

\section{INTRODUCTION}

Type 1 diabetes is a chronic autoimmune disorder that results from the tissue specific destruction of insulin producing beta-cells within pancreatic islets $(1,2)$. Human leukocyte antigen (HLA) genes, especially the class II DQ and DR alleles, confer significant disease risk (3-5). In addition to T1D risk genes, there are yet to be identified environment factors that lead to a loss of tolerance to insulin and other beta cell proteins. It is now appreciated that T1D develops in stages prior to the clinical onset of symptoms and these stages are defined with the presence of islet autoantibodies (6), those directed against insulin, glutamic acid decarboxylase (GAD), islet antigen 2 (IA-2), and zinc transporter 8 (ZnT8). From prospective birth cohort studies, if an at-risk child has two or more islet autoantibodies, there is $\sim 85 \%$ chance of developing T1D within 15 years and a nearly $100 \%$ lifetime risk for disease development (7). With the ability to stage the disease process and an increasing incidence over the last two decades (8), a number of largescale immune intervention trials have been completed trying to delay or prevent the onset of clinical disease. Many of these trials have used formulations of insulin (subcutaneous, intranasal, oral, and intradermal) as an antigen specific therapy (9-13). Unfortunately, the trials have been of limited clinical benefit and there is a need for safe and specific therapies to prevent the onset of T1D (14). We believe 


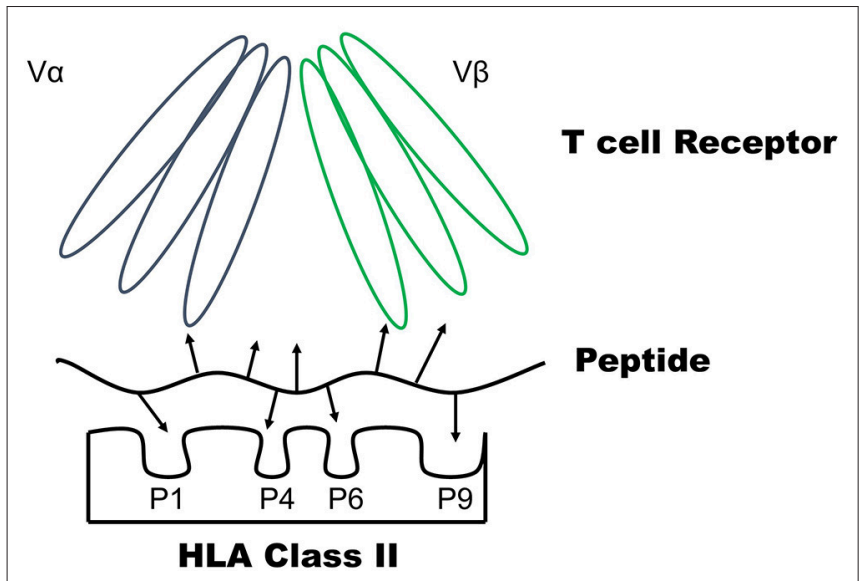

FIGURE 1 | The trimolecular complex consists of a CD4 T cell receptor-Peptide-HLA class II molecule. The peptide binding groove of the HLA class II molecule consists of pockets (P1, P4, P6, and P9) which bind amino acid side chains to anchor a peptide. The arrows of the peptide represent amino acid side chains. The T cell receptor is comprised of alpha and beta chains with three complementary determining regions (CDR) each. The $T$ cell receptor interacts with both peptide amino acid side chains and those located on the HLA molecule to become activated.

understanding the immunology within the target tissue, pancreatic islets, will lead to improved markers of disease activity and therapies to delay T1D onset (15). This has been challenging due to the anatomic location of the pancreas and dual function as both an exocrine and endocrine organ. However, recent efforts and advances in technology have made the study of pancreatic islets from recent onset T1D organ donors possible. Here we review the progress made in understanding the reactivity of islet infiltrating CD4 T cells with a focus on the trimolecular complex of T cell receptor-peptide-HLA molecule (Figure 1).

\section{STAGES OF T1D DEVELOPMENT}

At the current time, a significant amount of understanding surrounds the natural history of T1D development. Much of our understanding comes from both animal models of disease development and birth cohort studies that have followed genetically at-risk children (i.e., those with high risk HLA class II DQ and DR alleles) prospectively from birth to disease onset. These large epidemiology studies have taken place in the United States, Diabetes AutoImmunity Study in the Young (DAISY) (16), and Europe, including the Type 1 Diabetes Prediction and Prevention Study (DIPP) in Finland (17), and BABYDIAB studies in Germany (18). All three studies measured islet autoantibodies from the peripheral blood at regular time intervals (every 3-6 months) and showed that the presence of two or more islet autoantibodies marks the start of T1D, as nearly all of these genetically at risk children and adolescents develop clinical T1D, indicated by elevated blood glucose, insulin deficiency, and the need for exogenous insulin treatment. Notably, islet autoantibodies are markers of a disease state (islet autoimmunity) but not disease activity as antibodies can be present for years prior to clinical T1D presentation (19). The preclinical phase of T1D is now staged by the presence of islet autoantibodies and beta cell function, as measured by an oral glucose tolerance test (6). Stage 1 is the presence of two or more islet autoantibodies with no dysglycemia, Stage 2 encompasses those with autoantibodies and metabolic abnormalities, and Stage 3 is prototypical new-onset T1D in which an individual meets diagnostic blood glucose criteria for diabetes and the presence of islet autoantibodies (20). This staging paradigm leads to T1D being predictable and the ability to perform clinical intervention trials prior to a significant loss of beta cell function, with these trials previously reviewed (21).

Significant insights into disease pathogenesis come from the studying of animal models of autoimmune diabetes (22). The non-obese diabetic (NOD) mouse is a spontaneous model of autoimmune diabetes and shares many similarities with human disease (23). Both have major histocompatibility (MHC) class II genes that confer disease risk, NOD mice develop autoantibodies to insulin prior to hyperglycemia, and immune cells including $\mathrm{T}$ cells infiltrate the pancreatic islets (termed insulitis) in these mice. Disease specific $\mathrm{T}$ cells from the islets and pancreatic lymph nodes reveal that insulin is a critical self-antigen in the disease process (24-29). A fragment of the insulin B chain, amino acids 9-23 (B:9-23), is a CD4 T cell epitope and mutation of a single amino acid within the $\mathrm{B}$ chain (B16 tyrosine to alanine) results in mice maintaining normoglycemia without insulitis (27). This is not the case for other beta cell antigens including GAD, islet antigen 2 and glucose-6-phosphatase catalytic subunit-related protein (30-32) with the exception of chromogranin A, elimination of which results in significant protection from islet autoimmunity in NOD mice (33).

These insights from the NOD have translated to human disease in that insulin B:9-23 reactive $T$ cells have been identified within the islets of recent onset organ donors and in the peripheral blood of T1D patients (34-38). Notably insulin B:9-23 has an identical amino acid sequence in mouse and humans. Further support for insulin as a key self-antigen in a subset of T1D patients comes from the TEDDY study, The Environmental Determinants of Diabetes in the Young, which is an international multicenter prospective study evaluating environmental factors that may lead to the development of autoantibodies (islet autoimmunity) and eventual T1D (39). It is becoming appreciated that genetically at-risk children present with a different initial islet autoantibody that are correlated to HLADQ-DR genotypes. The presence of HLA-DR4-DQ8 haplotype (DR and DQ are in linkage disequilibrium on chromosome 6) is associated with insulin autoimmunity, while the DR3-DQ2 haplotype may reflect initial autoimmunity to GAD (40). These important findings indicate: (1) T1D risk genes are strongly associated with markers of an adaptive immune response to self-antigen and (2) there is disease heterogeneity such that subsets of patients may be defined by the presence of given HLA genes.

Another animal model of autoimmune diabetes that has been instrumental in understanding mechanisms of 
disease development is the BioBreeding rat. In these models there are diabetes prone animals that develop spontaneous islet infiltration, and separately diabetes resistant rats in which diabetes is induced with a viral infection or other stimulus of innate immune system activation (41). The use of an environmental trigger, such as a viral infection, may mimic an environmental exposure needed to induce human islet autoimmunity, and eventual T1D in a genetically susceptible individual.

Animal models unfortunately have not been as robust of a model for clinical therapeutics (42). The potential reasons for this are many, including dose, route, and timing of an intervention in the disease process. For example, antigen specific therapies tend to work well to prevent NOD diabetes onset when administered early in the disease process (e.g., before the development of insulin autoantibodies) but become less effective as the disease progresses (43). In contrast, anti-CD3 monoclonal antibodies are able to delay disease onset when administered later in the NOD disease course (42). Just as there are different animal models of T1D with spontaneous and inducible disease processes, human T1D is likely not a single disease. There is disease heterogeneity and the need exists to understand different subtypes of the condition, i.e., those that have a distinct pathophysiologic mechanism leading to T1D development (44), to improve the development of disease modifying therapies for T1D. As HLA class II genes confer genetic risk and function to present processed antigens to $\mathrm{CD} 4 \mathrm{~T}$ cells, understanding this trimolecular complex (Figure 1) within the target tissue (pancreatic islets) in human disease is critical for disease prevention and reversal $(45,46)$.

\section{NETWORK FOR PANCREATIC ORGAN DONORS (NPOD)}

The Network for Pancreatic Organ Donors (nPOD, http://www. jdrfnpod.org/) was established in 2007 to address the gap in the field to study the target organ in autoimmune T1D (47). Tissues from organ donors are collected and distributed to investigators for the study into the pathogenesis of human T1D. To date over 150 cases have been collected from T1D patients, over 150 non-diabetic donors and several dozens with autoantibodies but no clinical diabetes. This large and collaborative consortium has provided the frame work to study the human pancreas, islets embedded within the pancreas, pancreatic lymph nodes, and spleen in those with and without disease. Many insights have been gleaned from a decade of studies and recently reviewed $(48,49)$.

Prior to the efforts of nPOD, most of the knowledge regarding $\mathrm{T}$ cell reactivity came from the study of rare antigen specific cells in the peripheral blood with multiple groups cloning islet reactive T cells $(35,36,50-53)$. Outside of the peripheral blood, Kent and colleagues cloned insulin A chain reactive CD4 T cells from the pancreatic lymph nodes of an individual with established disease (54). However, in the last 3 years, three independent laboratories have reported on the antigen specificity of human islet derived CD4 T cells from recent onset T1D organ donors.

\section{ANTIGEN REPERTOIRE OF HUMAN ISLET INFILTRATING T CELLS}

In 2015, Mannering and colleagues reported the first results of cloning islet resident CD4 T cells from a deceased T1D organ donor (19 year-old with 3 years of T1D) (55). The donor had residual insulin staining within islets and hand-picked islets were cultured under conditions to promote $\mathrm{T}$ cell growth. Outgrowths of T cells were apparent and these cells were then single cell sorted using flow cytometry. Clones were established and then tested for reactivity to overlapping peptides of proinsulin and 26 peptides derived from other islet autoantigens-GAD65, IA-2, IGRP, and ZnT8. Epstein Barr Virus (EBV) transformed B cells from the donor were used as antigen presenting cells (APCs) in these T cell stimulation assays. Remarkably, 14 out of 53 tested CD4 T cell clones (26\%) responded to six overlapping peptides within the Cpeptide region of proinsulin (55) (Figure 2). The HLA restriction element was predominantly DQ8 and one clone responded to a C-peptide fragment presented by DQ8 trans. HLA-DQ8 (DQA*03:01, DQB*03:02) is present in $\sim 60 \%$ of all T1D patients and those at risk and confers an odds ratio for disease development of 6.5-11 (3). HLA-DQ2 (DQA*05:01, DQB*02:01) is also present in about $1 / 3 \mathrm{~T} 1 \mathrm{D}$ patients, and trans dimers can be formed where the beta alpha chain of DQ2 pairs with the beta chain of DQ8 (DQ8 trans: DQA*05:01, DQB*03:02), which may present unique epitopes to autoreactive CD4 T cells in T1D $(53,56,57)$.

Using a similar approach, Kent and colleagues cloned CD4 T cells from hand-picked islets of nine recent onset organ donors with T1D (58). In addition to growing $\mathrm{T}$ cell lines directly from islets, dispersed islets were stained, flow sorted for CD4 and CD8 cells and then expanded to establish ex vivo $\mathrm{T}$ cell lines. Fifty of the CD4 T cell lines were tested for antigen specificity using autologous EBV transformed B cells as APCs and a large panel of known or putative islet antigens including some which were post-translationally modified. Antigen specificity was identified in $17 / 50$ (34\%) of the tested $\mathrm{T}$ cell lines with a wide array of antigens represented including some which may represent post-translationally modified peptides (58, 59). These $\mathrm{T}$ cell lines predominantly secreted inflammatory cytokines such as IFN- $\gamma$, TNF- $\alpha$, and IL- 2 in response to their cognate peptide/HLA.

We used an alternate but complementary approach to study islet infiltrating $\mathrm{T}$ cells from three recent onset T1D organ donors, all of whom had insulitis and the T1D risk HLA-DQ8 allele (37). Hand-picked islets underwent short-term culture ( $\sim 3-4$ days) followed by single cell flow sorting for CD4 and CD8 cells. Instead of attempting to expand the single $\mathrm{T}$ cells, we sequenced the alpha and beta chains of the TCR of each individual cell. This provided insights into the diversity of the TCR repertoire of islet infiltrating $\mathrm{T}$ cells. We were able to isolate hundreds to thousands of $\mathrm{T}$ cells from 500 to 1,500 islet equivalents. CD8 $\mathrm{T}$ cells were more clonally expanded in these donors as 


\title{
Human Proinsulin
}

\author{
B Chain C-peptide A Chain
}

FVNQHLCGSHLVEALYLVCGERGFFYTPKTRREAEDLQVGQVELGGGPGAGSLQPLALEGSLQKRGIVEQCCTSICSLYQLENYCN

FIGURE 2 | Amino acid sequence of human proinsulin with shaded areas representing CD4 T cell epitopes recognized by islet derived T cells. T cells obtained from the insulitis lesions of recent onset T1D organ donors respond to epitopes within the shaded area of the insulin B chain, the B:9-23 region, and C-peptide including the amino acid sequence GQVELGGG which forms a portion of hybrid insulin peptides. These islet derived T cells are predominantly activated by peptides presented by HLA-DQ8.

$1 / 3$ to $1 / 2$ of all full length receptors were detected more than twice in the same donor (37). For CD4 T cells, only 15-20\% of the sequences were detected more than twice from two of the donors (37). While none of the identical sequences were shared between the three patients, it could due to the limited number of cases studied and further efforts may reveal public TCRs shared across patients.

To test antigen specificity, the TCR sequences from CD4 T cells were transduced into an immortalized TCR null cell line, thus making a single TCR transductant, and screened against overlapping preproinsulin peptides and other characterized islet antigens derived from peripheral blood $\mathrm{T}$ cell reactivity of patients. These TCR transductants are readily expanded in culture and provide a robust reagent to determine antigen specificity as these cells secrete IL-2 when the TCR engages cognate peptide/HLA (60). From 85 selected CD4 TCR transductants, 3 responded to peptides within proinsulin (37). Two TCRs from two separate donors responded to insulin B:9-23 presented by DQ8 and one TCR responded to C-peptide 19-35 presented by DQ8 trans (Figure 2). Importantly, the insulin B:923 responding $\mathrm{T}$ cells also responded to whole islets as antigen when presented by APCs bearing DQ8. Notably, reactivity to the DQ8 trans epitope within C-peptide is identical to that reported by Mannering and colleagues in a separate patient (55). This raises the distinct possibility that there are common epitopes within proinsulin, insulin B:9-23 and C-peptide 19-35, that stimulate islet infiltrating CD4 $\mathrm{T}$ cells even after the clinical onset of T1D.

Further research is underway to characterize the antigen specificity of the remaining CD4 TCR transductants and in a similar manner the CD8 $\mathrm{T}$ cell specificities and their HLA restriction elements. It is notable that the majority of the $\mathrm{T}$ cell lines, clones, and transductants reported on to date have unknown antigen specificities. Developing high or moderate throughput screening systems will aid in this endeavor. As TCR transductants are engineered $\mathrm{T}$ cells, these cells are amenable to fluorescent reporter systems based upon TCR stimulation, thereby providing the ability to combine multiple $\mathrm{T}$ cells into a single well of a stimulation assay. The use of human islet extracts as a source of antigen, including those cultured with agents that induce beta cell "stress," may provide tools to determine mechanisms by which autoantigens are formed in various disease conditions. Finally, combinatorial peptide libraries provide another avenue to define ligands for the islet derived $\mathrm{T}$ cell clones, lines, and transductants which have had success in other immune mediated diseases $(61,62)$.

\section{IMPLICATIONS FOR STUDYING TISSUE SPECIFIC T CELLS IN T1D}

For T1D, understanding the specificities and antigen receptor repertoire of those $\mathrm{T}$ cells within the target tissue will provide novel insights into disease pathogenesis and help to further dissect disease heterogeneity. Studying tissue specific $\mathrm{T}$ cells also provides an avenue to develop biomarkers to assess disease activity and monitoring immune responses to therapies. Islet autoantibodies mark a disease state in which the adaptive immune response has targeted pancreatic islets; however, these do not correlate to disease activity (i.e., insulitis and beta cell destruction). Conversely, $\mathrm{T}$ cells can cause tissue specific destruction and may provide markers of an active disease state, especially those cells that circulate in the peripheral blood. Of note, insulin B:9-23 reactivity has been detected in the islets of multiple T1D organ donors and peripheral blood of T1D patients (34-38). Further understanding the TCR repertoires across patients holds potential for developing a non-cell based biomarker assay as compared to traditional assays using fluorescent multimers $(63,64)$ and functional assays such as cytokine enzyme linked ImmunoSpot (ELISPOT) (65, 66). As immunosequencing technologies continue to advance, combined with machine learning algorithms, the potential exists to understand clonally expanded TCR repertoires and their ligands in disease states (67).

One of the major goals of studying human islet infiltrating $\mathrm{T}$ cells is to apply this knowledge to the development of therapies to prevent disease onset, induce tissue specific tolerance, and ultimately reverse the disease process. As mentioned previously, T1D does not represent a single disease pathogenesis and there are likely different mechanisms or pathways which lead to the immune system losing tolerance to insulin producing beta cells (44). It is important to understand these pathways and identify the different patient subsets or endotypes who share similar features to improve disease modifying therapies within T1D.

Antigen specific therapy has long held promise to both delete effector T cells and induce regulatory T cells to self-antigens (68). By understanding $\mathrm{T}$ cell reactivity within human T1D islets, it is our belief that antigen specific therapy can be better designed and subsets of patients identified with these $\mathrm{T}$ cell responses in their peripheral blood. It is conceivable that whole antigens (e.g., preproinsulin) or multiple relevant peptides need to be administered to patients with these reactivities. For example, a subset of patients may have dominant $\mathrm{T}$ cell responses directed toward insulin epitopes and benefit to proinsulin based antigen 
therapies, while other patients may have predominant GAD reactivity and would respond to GAD based antigen therapies. This rationale is in line with the findings from TEDDY indicating that a subset of children present with initial insulin autoimmunity or GAD autoimmunity based upon HLA genotype (40). An important caveat to mention is the fact that combination therapy will likely be needed based upon the stage of T1D treated (14). At new-onset T1D (Stage 3) induction therapy could be followed by antigen specific therapy in an attempt to induce antigen specific tolerance. Induction therapies could include a monoclonal antibody directed against CD2 or CD3 on T cells (69-72), CD20 on B cells (73), CD80/86 on APCs (74), or polyclonal anti-thymocyte globuliln (ATG) (75), which have all shown short-term ability to preserve residual beta cell function in clinical trials with new-onset T1D patients.

Another promising disease modifying therapy uses small "druglike" molecules to block self-antigens presented by HLADQ8 $(76,77)$. DQ8 is common in T1D, confers significant genetic risk and is actively involved in disease pathogenesis as the vast majority of islet derived CD4 T cells studied to date are activated by proinsulin peptides presented by DQ8 (58). Methyldopa (Aldomet), a clinically well-established oral medication used to treat hypertension in children and adults for $>50$ years (78), was discovered to bind the antigen-binding cleft of DQ8, and block peptide presentation and subsequent $\mathrm{T}$ cell activation to selfantigens (insulin and $\alpha$-gliadin) (77). Remarkably, methyldopa did not alter a $\mathrm{T}$ cell response to an influenza epitope presented by DQ8. In a proof of concept clinical trial, recent onset T1D patients were genetically selected for DQ8 and administered methyldopa (www.clinicaltrials.gov NCT01883804). Methyldopa specifically blocked DQ8, not DR4 or DQ2, in these patients and lessened the inflammatory response of insulin specific $\mathrm{T}$ cells

\section{REFERENCES}

1. Bluestone JA, Herold K, Eisenbarth G. Genetics, pathogenesis and clinical interventions in type 1 diabetes. Nature. (2010) 464:1293-300. doi: $10.1038 /$ nature 08933

2. Atkinson MA, Eisenbarth GS, Michels AW. Type 1 diabetes. Lancet. (2014) 383:69-82. doi: 10.1016/S0140-6736(13)60591-7

3. Erlich H, Valdes AM, Noble J, Carlson JA, Varney M, Concannon P, et al. HLA DR-DQ haplotypes and genotypes and type 1 diabetes risk: analysis of the type 1 diabetes genetics consortium families. Diabetes. (2008) 57:1084-92. doi: $10.2337 / \mathrm{db} 07-1331$

4. Concannon P, Rich SS, Nepom GT. Genetics of type 1A diabetes. N Engl J Med. (2009) 360:1646-54. doi: 10.1056/NEJMra0808284

5. Hu X, Deutsch AJ, Lenz TL, Onengut-Gumuscu S, Han B, Chen WM, et al. Additive and interaction effects at three amino acid positions in HLA-DQ and HLA-DR molecules drive type 1 diabetes risk. Nat Genet. (2015) 47:898-905. doi: 10.1038/ng.3353

6. Semenkovich CF, Danska J, Darsow T, Dunne JL, Huttenhower C, Insel RA, et al. American Diabetes association and JDRF research symposium: diabetes and the microbiome. Diabetes. (2015) 64:3967-77. doi: 10.2337/db15-0597

7. Ziegler AG, Rewers M, Simell O, Simell T, Lempainen J, Steck A, et al. Seroconversion to multiple islet autoantibodies and risk of progression to diabetes in children. JAMA. (2013) 309:2473-9. doi: 10.1001/jama.2013.6285

8. Mayer-Davis EJ, Lawrence JM, Dabelea D, Divers J, Isom S, Dolan L, et al. Incidence trends of type 1 and type 2 diabetes among youths, 2002-2012. N Engl J Med. (2017) 376:1419-29. doi: 10.1056/NEJMoa1610187
(77). As many autoimmune diseases are associated with specific HLA class II genes $(79,80)$, genetically selecting patients and treating with drugs to block self-antigen T cell activation by these HLA molecules has broad applicability to treating not only T1D but other autoimmune diseases.

\section{CONCLUSIONS}

There is a need to study $\mathrm{T}$ cells within the target tissue, pancreatic islets, of T1D patients. This need is being met through collaborative research efforts such as the Network for Pancreatic Organ Donors (nPOD). Findings from independent laboratories are defining the components of the trimolecular complex, TCRpeptide-HLA, within human islet infiltrating CD4 T cells. This understanding provides a framework to understand disease heterogeneity and develop biomarkers of disease activity, which hold promise for disease monitoring and timing of therapeutic interventions. Ultimately, this understanding will aid in the design and development of improved therapies aimed at inducing tolerance to islet antigens and preventing T1D onset.

\section{AUTHOR CONTRIBUTIONS}

MN and AM both wrote and edited the manuscript.

\section{FUNDING}

This work was supported by grants from the National Institutes of Health (DK108868, DK032083, DK110845, DK099317, and DK104223), Juvenile Diabetes Research Foundation, and the Children's Diabetes Foundation.
9. Diabetes Prevention Trial-Type 1 Diabetes Study Group. Effects of insulin in relatives of patients with type 1 diabetes mellitus. N Engl J Med. (2002) 346:1685-91. doi: 10.1056/NEJMoa012350

10. Skyler JS, Krischer JP, Wolfsdorf J, Cowie C, Palmer JP, Greenbaum C, et al. Effects of oral insulin in relatives of patients with type 1 diabetes: the diabetes Prevention Trial-Type 1. Diabetes Care. (2005) 28:1068-76. doi: 10.2337/diacare.28.5.1068

11. Nanto-Salonen K, Kupila A, Simell S, Siljander H, Salonsaari T, Hekkala A, et al. Nasal insulin to prevent type 1 diabetes in children with HLA genotypes and autoantibodies conferring increased risk of disease: a double-blind, randomised controlled trial. Lancet. (2008) 372:1746-55. doi: 10.1016/S0140-6736(08)61309-4

12. Alhadj Ali M, Liu YF, Arif S, Tatovic D, Shariff H, Gibson VB, et al. Metabolic and immune effects of immunotherapy with proinsulin peptide in human new-onset type 1 diabetes. Sci Transl Med. (2017) 9:eaaf7779. doi: 10.1126/scitranslmed.aaf7779

13. Krischer JP, Schatz DA, Bundy B, Skyler JS, Greenbaum CJ. Effect of oral insulin on prevention of diabetes in relatives of patients with type 1 diabetes: a randomized clinical trial. JAMA. (2017) 318:1891-902. doi: 10.1001/jama.2017.17070

14. Skyler JS. Prevention and reversal of type 1 diabetes-past challenges and future opportunities. Diabetes Care. (2015) 38:997-1007. doi: $10.2337 / \mathrm{dc} 15-0349$

15. Nakayama M, Simmons KM, Michels AW. Molecular interactions governing autoantigen presentation in type 1 diabetes. Curr Diab Rep. (2015) 15:113. doi: $10.1007 / \mathrm{s} 11892-015-0689-\mathrm{z}$ 
16. Barker JM, Barriga KJ, Yu L, Miao D, Erlich HA, Norris JM, et al. Prediction of autoantibody positivity and progression to type 1 diabetes: Diabetes Autoimmunity Study in the Young (DAISY). J Clin Endocrinol Metab. (2004) 89:3896-902. doi: 10.1210/jc.2003-031887

17. Kupila A, Keskinen P, Simell T, Erkkila S, Arvilommi P, Korhonen S, et al. Genetic risk determines the emergence of diabetes-associated autoantibodies in young children. Diabetes. (2002) 51:646-51. doi: 10.2337/diabetes.51.3.646

18. Ziegler AG, Hummel M, Schenker M, Bonifacio E. Autoantibody appearance and risk for development of childhood diabetes in offspring of parents with type 1 diabetes: the 2-year analysis of the German BABYDIAB Study. Diabetes. (1999) 48:460-8. doi: 10.2337/diabetes.48.3.460

19. Bonifacio E. Predicting type 1 diabetes using biomarkers. Diabetes Care. (2015) 38:989-96. doi: 10.2337/dc15-0101

20. American Diabetes Association. Classification and diagnosis of diabetes: standards of medical care in diabetes-2018. Diabetes Care. (2018) 41(Suppl. 1):S13-27. doi: $10.2337 / \mathrm{dc} 18-\mathrm{S} 002$

21. Simmons KM, Gottlieb PA, Michels AW. Immune Intervention and preservation of pancreatic beta cell function in type 1 diabetes. Curr Diab Rep. (2016) 16:97. doi: 10.1007/s11892-016-0793-8

22. Chaparro RJ, Dilorenzo TP. An update on the use of NOD mice to study autoimmune (Type 1) diabetes. Expert Rev Clin Immunol. (2010) 6:939-55. doi: $10.1586 /$ eci. 10.68

23. Driver JP, Serreze DV, Chen YG. Mouse models for the study of autoimmune type 1 diabetes: a NOD to similarities and differences to human disease. Semin Immunopathol. (2011) 33:67-87. doi: 10.1007/s00281-010-0204-1

24. Daniel D, Gill RG, Schloot N, Wegmann D. Epitope specificity, cytokine production profile and diabetogenic activity of insulin-specific $\mathrm{T}$ cell clones isolated from NOD mice. Eur J Immunol. (1995) 25:1056-62. doi: $10.1002 /$ eji.1830250430

25. French MB, Allison J, Cram DS, Thomas HE, Dempsey-Collier M, Silva A, et al. Transgenic expression of mouse proinsulin II prevents diabetes in nonobese diabetic mice. Diabetes. (1997) 46:34-9. doi: 10.2337/diab.46.1.34

26. Jaeckel E, Lipes MA, von Boehmer H. Recessive tolerance to preproinsulin 2 reduces but does not abolish type 1 diabetes. Nat Immunol. (2004) 5:1028-35. doi: $10.1038 /$ ni1 120

27. Nakayama M, Abiru N, Moriyama H, Babaya N, Liu E, Miao D, et al. Prime role for an insulin epitope in the development of type 1 diabetes in NOD mice. Nature. (2005) 435:220-3. doi: 10.1038/nature03523

28. Stadinski BD, Zhang L, Crawford F, Marrack P, Eisenbarth GS, Kappler JW. Diabetogenic T cells recognize insulin bound to IAg7 in an unexpected, weakly binding register. Proc Natl Acad Sci USA. (2010) 107:10978-83. doi: 10.1073/pnas.1006545107

29. Crawford F, Stadinski B, Jin N, Michels A, Nakayama M, Pratt P, et al. Specificity and detection of insulin-reactive CD4+ T cells in type 1 diabetes in the nonobese diabetic (NOD) mouse. Proc Natl Acad Sci USA. (2011) 108:16729-34. doi: 10.1073/pnas.1113954108

30. Kubosaki A, Miura J, Notkins AL. IA-2 is not required for the development of diabetes in NOD mice. Diabetologia. (2004) 47:149-50. doi: $10.1007 / \mathrm{s} 00125-003-1252-\mathrm{z}$

31. Yamamoto T, Yamato E, Tashiro F, Sato T, Noso S, Ikegami H, et al. Development of autoimmune diabetes in glutamic acid decarboxylase 65 (GAD65) knockout NOD mice. Diabetologia. (2004) 47:221-4. doi: 10.1007/s00125-003-1296-0

32. Krishnamurthy B, Dudek NL, McKenzie MD, Purcell AW, Brooks AG, Gellert $\mathrm{S}$, et al. Responses against islet antigens in NOD mice are prevented by tolerance to proinsulin but not IGRP. J Clin Invest. (2006) 116:3258-65. doi: 10.1172/JCI29602

33. Baker RL, Bradley B, Wiles TA, Lindsay RS, Barbour G, Delong T, et al. Cutting edge: nonobese diabetic mice deficient in chromogranin a are protected from autoimmune diabetes. J Immunol. (2016) 196:39-43. doi: 10.4049/jimmunol.1501190

34. Alleva DG, Crowe PD, Jin L, Kwok WW, Ling N, Gottschalk M, et al. A disease-associated cellular immune response in type 1 diabetics to an immunodominant epitope of insulin. J Clin Invest. (2001) 107:173-80. doi: 10.1172/JCI8525

35. Yang J, Chow IT, Sosinowski T, Torres-Chinn N, Greenbaum CJ, James EA, et al. Autoreactive T cells specific for insulin B:11-23 recognize a low-affinity peptide register in human subjects with autoimmune diabetes. Proc Natl Acad Sci USA. (2014) 111:14840-5. doi: 10.1073/pnas.1416864111

36. Nakayama M, McDaniel K, Fitzgerald-Miller L, Kiekhaefer C, Snell-Bergeon JK, Davidson HW, et al. Regulatory vs. inflammatory cytokine T-cell responses to mutated insulin peptides in healthy and type 1 diabetic subjects. Proc Natl Acad Sci USA. (2015) 112:4429-34. doi: 10.1073/pnas.1502967112

37. Michels AW, Landry LG, McDaniel KA, Yu L, Campbell-Thompson M, Kwok WW, et al. Islet-Derived CD4 T cells targeting proinsulin in human autoimmune diabetes. Diabetes. (2017) 66:722-34. doi: 10.2337/db16-1025

38. Spanier JA, Sahli NL, Wilson JC, Martinov T, Dileepan T, Burrack AL, et al. Increased effector memory insulin-specific CD4(+) $\mathrm{T}$ cells correlate with insulin autoantibodies in patients with recent-onset type 1 diabetes. Diabetes. (2017) 66:3051-60. doi: 10.2337/db17-0666

39. Steck AK, Vehik K, Bonifacio E, Lernmark A, Ziegler AG, Hagopian WA, et al. Predictors of progression from the appearance of islet autoantibodies to early childhood diabetes: The Environmental Determinants of Diabetes in the Young (TEDDY). Diabetes Care. (2015) 38:808-13. doi: 10.2337/dc14-2426

40. Krischer JP, Lynch KF, Schatz DA, Ilonen J, Lernmark A, Hagopian WA, et al. The 6 year incidence of diabetes-associated autoantibodies in genetically at-risk children: the TEDDY study. Diabetologia. (2015) 58:980-7. doi: 10.1007/s00125-015-3514-y

41. Bortell R, Yang C. The BB rat as a model of human type 1 diabetes. Methods Mol Biol. (2012) 933:31-44. doi: 10.1007/978-1-62703-068-7 3

42. Reed JC, Herold KC. Thinking bedside at the bench: the NOD mouse model of T1DM. Nat Rev Endocrinol. (2015) 11:308-14. doi: 10.1038/nrendo.2014.236

43. Coppieters KT, Harrison LC, von Herrath MG. Trials in type 1 diabetes: Antigen-specific therapies. Clin Immunol. (2013) 149:345-55. doi: 10.1016/j.clim.2013.02.002

44. Arif S, Leete P, Nguyen V, Marks K, Nor NM, Estorninho M, et al. Blood and islet phenotypes indicate immunological heterogeneity in type 1 diabetes. Diabetes. (2014) 63:3835-45. doi: 10.2337/db14-0365

45. Michels AW. Targeting the trimolecular complex. Clin Immunol. (2013) 149:339-44. doi: 10.1016/j.clim.2013.02.020

46. Michels AW. Targeting the trimolecular complex: the pathway towards type 1 diabetes prevention. Diabetes Technol Ther. (2013) 15 (Suppl. 2):S2-8-s2-12. doi: 10.1089/dia.2013.0114

47. Pugliese A, Yang M, Kusmarteva I, Heiple T, Vendrame F, Wasserfall C, et al. The juvenile diabetes research foundation network for pancreatic organ donors with diabetes (nPOD) Program: goals, operational model and emerging findings. Pediatr Diabetes. (2014) 15:1-9. doi: 10.1111/pedi.12097

48. Kaddis JS, Pugliese A, Atkinson MA. A run on the biobank: what have we learned about type 1 diabetes from the nPOD tissue repository? Curr Opin Endocrinol Diabetes Obes. (2015) 22:290-5. doi: 10.1097/MED.0000000000000171

49. Kent SC, Mannering SI, Michels AW, Babon JAB. Deciphering the pathogenesis of human Type 1 Diabetes (T1D) by interrogating $\mathrm{T}$ cells from the "scene of the crime." Curr Diab Rep. (2017) 17:95. doi: 10.1007/s11892-017-0915-y

50. Mallone R, Kochik SA, Laughlin EM, Gersuk VH, Reijonen H, Kwok WW, et al. Differential recognition and activation thresholds in human autoreactive GAD-specific T-cells. Diabetes. (2004) 53:971-7. doi: $10.2337 /$ diabetes.53.4.971

51. Mannering SI, Harrison LC, Williamson NA, Morris JS, Thearle DJ, Jensen KP, et al. The insulin A-chain epitope recognized by human $\mathrm{T}$ cells is posttranslationally modified. J Exp Med. (2005) 202:1191-7. doi: 10.1084/jem.20051251

52. Di Lorenzo TP, Peakman M, Roep BO. Translational mini-review series on type 1 diabetes: systematic analysis of T cell epitopes in autoimmune diabetes. Clin Exp Immunol. (2007) 148:1-16. doi: 10.1111/j.1365-2249.2006.03244.x

53. Eerligh P, van Lummel M, Zaldumbide A, Moustakas AK, Duinkerken G, Bondinas G, et al. Functional consequences of HLA-DQ8 homozygosity versus heterozygosity for islet autoimmunity in type 1 diabetes. Genes Immun. (2011) 12:415-27. doi: 10.1038/gene.2011.24

54. Kent SC, Chen Y, Bregoli L, Clemmings SM, Kenyon NS, Ricordi $\mathrm{C}$, et al. Expanded $\mathrm{T}$ cells from pancreatic lymph nodes of type 1 diabetic subjects recognize an insulin epitope. Nature. (2005) 435:224-8. doi: $10.1038 /$ nature 03625 
55. Pathiraja V, Kuehlich JP, Campbell PD, Krishnamurthy B, Loudovaris T, Coates PT, et al. Proinsulin-specific, HLA-DQ8, and HLA-DQ8-transdimerrestricted CD $4+\mathrm{T}$ cells infiltrate islets in type 1 diabetes. Diabetes. (2015) 64:172-82. doi: $10.2337 / \mathrm{db} 14-0858$

56. Koeleman BP, Lie BA, Undlien DE, Dudbridge F, Thorsby E, de Vries $\mathrm{RR}$, et al. Genotype effects and epistasis in type 1 diabetes and HLADQ trans dimer associations with disease. Genes Immun. (2004) 5:381-8. doi: 10.1038/sj.gene.6364106

57. van Lummel $\mathrm{M}$, van Veelen PA, Zaldumbide A, de $\mathrm{Ru} A$, Janssen GM, Moustakas AK, et al. Type 1 diabetes-associated HLA-DQ8 transdimer accommodates a unique peptide repertoire. J Biol Chem. (2012) 287:9514-24. doi: 10.1074/jbc.M111.313940

58. Babon JA, DeNicola ME, Blodgett DM, Crevecoeur I, Buttrick TS, Maehr R, et al. Analysis of self-antigen specificity of islet-infiltrating T cells from human donors with type 1 diabetes. Nat Med. (2016) 22:1482-7. doi: 10.1038/nm.4203

59. Delong T, Wiles TA, Baker RL, Bradley B, Barbour G, Reisdorph R, et al. Pathogenic CD4 T cells in type 1 diabetes recognize epitopes formed by peptide fusion. Science. (2016) 351:711-4. doi: 10.1126/science.aad2791

60. Williams T, Krovi HS, Landry LG, Crawford F, Jin N, Hohenstein A, et al. Development of $\mathrm{T}$ cell lines sensitive to antigen stimulation. J Immunol Methods. (2018) 462:65-73. doi: 10.1016/j.jim.2018.08.011

61. Pinilla C, Appel JR, Judkowski V, Houghten RA. Identification of B cell and T cell epitopes using synthetic peptide combinatorial libraries. Curr Protoc Immunol. (2012) 9:9.5.1-9.5.16. doi: 10.1002/0471142735.im0905s99

62. Falta MT, Pinilla C, Mack DG, Tinega AN, Crawford F, Giulianotti M, et al. Identification of beryllium-dependent peptides recognized by CD4+ $\mathrm{T}$ cells in chronic beryllium disease. J Exp Med. (2013) 210:1403-18. doi: 10.1084/jem.20122426

63. James EA, Bui J, Berger D, Huston L, Roti M, Kwok WW. Tetramerguided epitope mapping reveals broad, individualized repertoires of tetanus toxin-specific CD4+ T cells and suggests HLA-based differences in epitope recognition. Int Immunol. (2007) 19:1291-301. doi: 10.1093/intimm/dxm099

64. Velthuis JH, Unger WW, Abreu JR, Duinkerken G, Franken K, Peakman $\mathrm{M}$, et al. Simultaneous detection of circulating autoreactive CD8 + T-cells specific for different islet cell-associated epitopes using combinatorial MHC multimers. Diabetes. (2010) 59:1721-30. doi: 10.2337/db09-1486

65. Arif S, Tree TI, Astill TP, Tremble JM, Bishop AJ, Dayan CM, et al. Autoreactive $\mathrm{T}$ cell responses show proinflammatory polarization in diabetes but a regulatory phenotype in health. J Clin Invest. (2004) 113:451-63. doi: 10.1172/JCI19585

66. Nagata M, Kotani R, Moriyama H, Yokono K, Roep BO, Peakman M. Detection of autoreactive $\mathrm{T}$ cells in type 1 diabetes using coded autoantigens and an immunoglobulin-free cytokine ELISPOT assay: report from the fourth immunology of diabetes society T cell workshop. Ann N Y Acad Sci. (2004) 1037:10-5. doi: 10.1196/annals.1337.002

67. Glanville J, Huang H, Nau A, Hatton O, Wagar LE, Rubelt F, et al. Identifying specificity groups in the T cell receptor repertoire. Nature. (2017) 547:94-8. doi: 10.1038/nature22976

68. Roep BO, Wheeler DCS, Peakman M. Antigen-based immune modulation therapy for type 1 diabetes: the era of precision medicine. Lancet Diabetes Endocrinol. (2019) 7:65-74. doi: 10.1016/S2213-8587(18)30109-8

69. Herold KC, Hagopian W, Auger JA, Poumian-Ruiz E, Taylor L, Donaldson $\mathrm{D}$, et al. Anti-CD3 monoclonal antibody in new-onset type 1 diabetes mellitus. N Engl J Med. (2002) 346:1692-8. doi: 10.1056/NEJMoa0 12864

70. Keymeulen B, Vandemeulebroucke E, Ziegler AG, Mathieu C, Kaufman L, Hale G, et al. Insulin needs after CD3-antibody therapy in new-onset type 1 diabetes. N Engl J Med. (2005) 352:2598-608. doi: 10.1056/NEJMoa0 43980

71. Sherry N, Hagopian W, Ludvigsson J, Jain SM, Wahlen J, Ferry RJ Jr, et al. Teplizumab for treatment of type 1 diabetes (Protege study): 1-year results from a randomised, placebo-controlled trial. Lancet. (2011) 378:487-97. doi: 10.1016/S0140-6736(11)60931-8

72. Rigby MR, Harris KM, Pinckney A, DiMeglio LA, Rendell MS, Felner EI, et al. Alefacept provides sustained clinical and immunological effects in new-onset type 1 diabetes patients. J Clin Invest. (2015) 125:3285-96. doi: $10.1172 /$ JCI81722

73. Pescovitz MD, Greenbaum CJ, Krause-Steinrauf H, Becker DJ, Gitelman SE, Goland R, et al. Rituximab, B-lymphocyte depletion, and preservation of beta-cell function. N Engl J Med. (2009) 361:2143-52. doi: 10.1056/NEJMoa0904452

74. Orban T, Bundy B, Becker DJ, DiMeglio LA, Gitelman SE, Goland R, et al. Costimulation modulation with abatacept in patients with recent-onset type 1 diabetes: a randomised, double-blind, placebo-controlled trial. Lancet. (2011) 378:412-9. doi: 10.1016/S0140-6736(11)60886-6

75. Haller MJ, Schatz DA, Skyler JS, Krischer JP, Bundy BN, Miller JL, et al. Low-Dose Anti-Thymocyte Globulin (ATG) preserves beta-cell function and improves HbA1c in new-onset type 1 diabetes. Diabetes Care. (2018) 41:191725. doi: $10.2337 / \mathrm{dc} 18-0494$

76. Michels AW, Ostrov DA, Zhang L, Nakayama M, Fuse M, McDaniel $\mathrm{K}$, et al. Structure-based selection of small molecules to alter allelespecific MHC class II antigen presentation. J Immunol. (2011) 187:5921-30. doi: 10.4049/jimmunol.1100746

77. Ostrov DA, Alkanani A, McDaniel KA, Case S, Baschal EE, Pyle L, et al. Methyldopa blocks MHC class II binding to disease-specific antigens in autoimmune diabetes. J Clin Invest. (2018) 128:1888-902. doi: $10.1172 /$ JCI97739

78. Mah GT, Tejani AM, Musini VM. Methyldopa for primary hypertension. Cochrane Database Syst Rev. (2009) 4:Cd003893. doi: 10.1002/14651858.CD003893.pub2

79. Tsai S, Santamaria P. MHC class II polymorphisms, autoreactive T-cells, and autoimmunity. Front Immunol. (2013) 4:321. doi: 10.3389/fimmu.2013.00321

80. Dendrou CA, Petersen J, Rossjohn J, Fugger L. HLA variation and disease. Na Rev Immunol. (2018) 18:325-39. doi: 10.1038/nri.2017.143

Conflict of Interest Statement: AM and MN are inventors on an issued patent, Compounds That Modulate Autoimmunity and Methods of Using the Same, licensed to ImmunoMolecular Therapeutics, LLC. AM is a scientific cofounder of ImmunoMolecular Therapeutics.

Copyright (C) 2019 Nakayama and Michels. This is an open-access article distributed under the terms of the Creative Commons Attribution License (CC BY). The use, distribution or reproduction in other forums is permitted, provided the original author(s) and the copyright owner(s) are credited and that the original publication in this journal is cited, in accordance with accepted academic practice. No use, distribution or reproduction is permitted which does not comply with these terms. 